\title{
Pathways of Serine and Glycine Metabolism in Primary Culture of Ovine Fetal Hepatocytes
}

\author{
PATTI J. THUREEN, MICHAEL R. NARKEWICZ, FREDERICK C. BATTAGLIA, SUSAN TJOA, \\ AND PAUL V. FENNESSEY \\ Department of Pediatrics, Sections of Neonatology [P.J.T., F.C.B.], Gastroenterology, Hepatology and \\ Nutrition [M.R.N.], and Genetics [S.T., P.V.F.], University of Colorado Health Sciences Center,
}

Denver, Colorado 80262

\section{ABSTRACT
ABST}

Previous in vivo studies in the ovine fetus have demonstrated net serine production by the fetal liver, a pattern not seen in the adult sheep. The goal of this study was to determine the major metabolic pathways responsible for fetal hepatic serine production by using stable isotope methodology in primary culture of late gestation ovine fetal hepatocytes. Specifically selected tracers of glycine were added to individual cultures, with production of labeled serine determined after $24 \mathrm{~h}$ of incubation. When $\left[1-{ }^{13} \mathrm{C}_{1}\right]$ glycine or $\left[2-{ }^{13} \mathrm{C}_{1}\right]$ glycine was used as the initial tracer, serine enrichment at $24 \mathrm{~h}$ indicated that approximately $30 \%$ of serine production comes from glycine. Quantitative comparison of serine enrichment from these two tracers suggests that serine synthesis from glycine occurs via the combined action of the glycine cleavage enzyme system (GCE) and serine hydroxymethyltransferase (SHMT). Using $\left[1,2-{ }^{13} \mathrm{C}_{2}{ }^{15} \mathrm{~N}_{1}\right]$ glycine as the tracer, there was no significant increase in $\mathrm{M}+2$ glycine in the medium over $24 \mathrm{~h}$, suggesting no reversible transamination of glycine, and therefore no significant movement of glycine through the glyoxalate pathway. These data demonstrate that in primary culture of fetal ovine hepatoctyes, approximately $30 \%$ of serine biosynthesis is derived from glycine, primarily via the combined action of GCE and SHMT. (Pediatr Res 38: 775-782, 1995)
Abbreviations
SHMT, serine hydroxymethyltransferase GCE, glycine cleavage enzyme system
THF, tetrahydrofolate
M, mass (atomic mass unit, amu) of the natural ${ }^{12} \mathrm{C}$ or ${ }^{14} \mathrm{~N}$ isomer of serine or glycine
MPE, mole percent enrichment

During fetal life, amino acids are used for many functions such as precursors for protein synthesis and metabolic fuels, and for the synthesis of other carbon- and nitrogen-containing compounds including nucleic acids, glycogen, and lipid. There is increasing evidence that fetal amino acid metabolism has unique characteristics when compared with adult metabolism $(1,2)$. Some of these differences are due to ontologic changes in organ-specific amino acid metabolism (3). In particular, there appear to be differences in fetal hepatic serine metabolism when compared with adult hepatic serine metabolism (2, 4-8). In the sheep, in vivo studies have indicated that serine and glycine have unique fetal metabolic characteristics compared with those that have been demonstrated in adult animals of other species. Using the unique ability to chronically catheterize the ovine fetal liver, it has been demonstrated that in the

Received March 14, 1995; accepted June 6, 1995

Correspondence and reprint requests: Patti J. Thureen, M.D., Section of Neonatology, B-195, University of Colorado Health Sciences Center, 4200 East 9th Avenue, Denver, CO 80262 .

Supported in part by National Institutes of Health Grants HD29362-D1, 2P30 DK34914, 1P30 HD27827, HD01061-02, and HD27827-02. late-gestation ovine fetal liver there is net hepatic uptake of glycine with net hepatic release of serine $(2,7)$. In contrast, studies in the adult dog, cow, and rabbit have demonstrated a net hepatic uptake of both serine and glycine $(5,9-11)$.

In the fetus, serine is important for nucleotide biosynthesis and as a potential donor of methyl carbon (12). The metabolic precursors for fetal hepatic serine production are unknown. Studies suggest that glucose in the fetal rat (4) and glycine in the fetal sheep (2) are significant precursors of fetal hepatic serine biosynthesis.

The enzymatic pathways by which glycine carbon could contribute to serine synthesis are shown in Figure 1 and may include: 1) SHMT where glycine is combined with the donor methyl group derived from a non-glycine source, 2) coupling of GCE with SHMT such that 2 glycine molecules are used to form 1 molecule of serine, or 3) by a more indirect pathway involving the transamination of glycine to glyoxalate and the eventual contribution of glycine carbon to methylene-THF.

We have recently developed a system of primary culture of ovine fetal hepatocytes which maintains a pattern of net medium amino acid production and utilization similar to that seen 


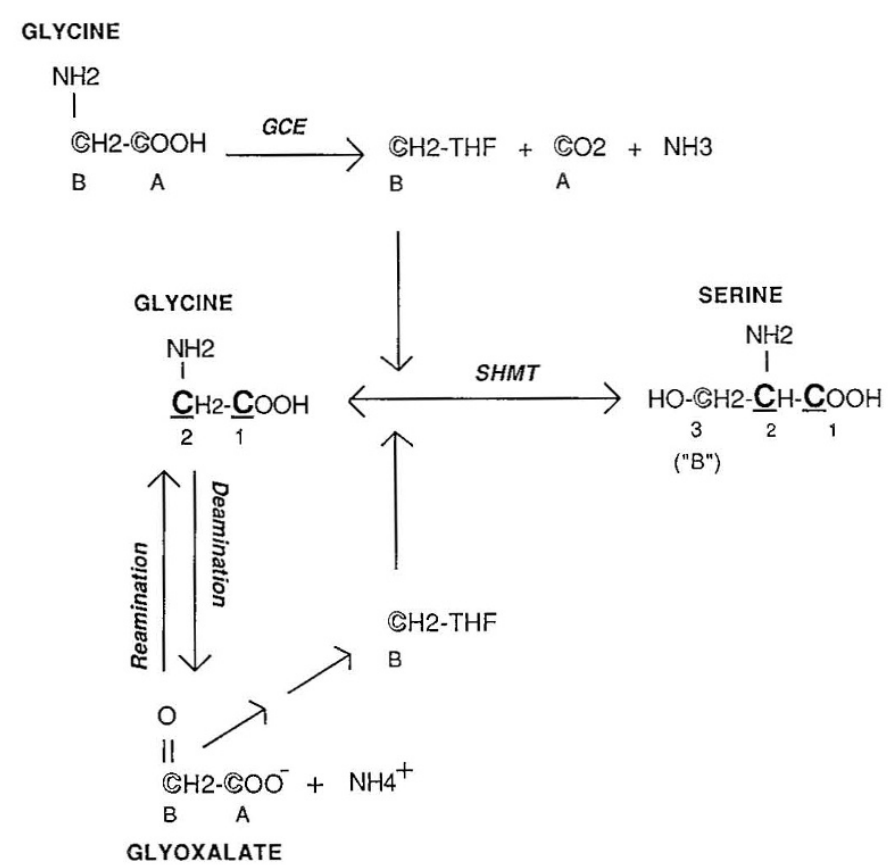

Figure 1. Metabolic pathways of serine and glycine interconversion. Possible pathways of serine production from glycine and the source of the different serine carbons when serine is produced from glycine. The 3 carbon (or the " $\mathrm{B}$ " carbon) of serine is provided by the intermediate $\mathrm{CH}_{2}$-THF $\left(N^{5}, N^{10}\right.$ methylene-tetrahydrofolic acid) which is produced from glycine by the action of GCE. An alternative way of contributing the " $B$ " carbon to the one-carbon pool is via transamination of glycine to glyoxalate with eventual production of $\mathrm{CH}_{2}$-THF. Serine carbons 1 and 2 come directly from glycine, which combines with $\mathrm{CH}_{2}$-THF via the enzyme SHMT.

across the fetal ovine liver in vivo (13). Specifically, there is a net production of serine and a net uptake of glycine. The aims of this study were: $l$ ) to compare stable isotope studies of serine biosynthesis in primary culture of fetal ovine hepatocytes with our previous in vivo studies, and 2) to identify the relative contribution of the specific pathways (i.e. GCE, SHMT, and glyoxalate pathways) by which glycine is converted to serine in primary fetal ovine hepatocytes using this tracer methodology.

\section{METHODS}

Cell isolation and primary culture of hepatocytes. Columbia-Rambouillet pregnant ewes were anesthetized with pentobarbital $(25 \mathrm{mg} / \mathrm{kg}$ i.v.). The fetus was delivered by cesarean section, anesthetized with pentobarbital $(20 \mathrm{mg} / \mathrm{kg})$, and heparinized (1000 U/kg of body weight). Hepatocytes were isolated from these late gestation fetal lambs by in situ perfusion and collagenase digestion as previously reported (13). Cell viability was assessed by trypan blue exclusion. Only cell isolations with $>92 \%$ viable cells were used for primary culture. After isolation, cells were resuspended in seeding medium (arginine-free minimal essential medium- $\alpha$, supplemented with $1.1 \mathrm{mM}$ glucose, $2 \mathrm{mM}$ lactate, $0.4 \mathrm{mM}$ ornithine (Life Technologies, Inc., Gaithersberg, MD); $10 \%$ fetal calf serum, $10 \mathrm{IU} / \mathrm{mL}$ penicillin, $100 \mu \mathrm{g} / \mathrm{mL}$ streptomycin, 50 $\mu \mathrm{g} / \mathrm{mL}$ kanamycin, and $10 \mathrm{nM}$ dexamethasone), and plated at
$2 \times 10^{6}$ cells $/ 25-\mathrm{mm}$ plate. Cells were incubated in humidified air $/ \mathrm{CO}_{2}(19: 1)$ at $37^{\circ} \mathrm{C}$ and the medium was changed every $24 \mathrm{~h}$. After adherence for $4-10 \mathrm{~h}$, the medium was changed to standard medium (arginine-free minimal essential medium- $\alpha$ supplemented with $1.1 \mathrm{mM}$ glucose, $2 \mathrm{mM}$ lactate, $0.4 \mathrm{mM}$ ornithine, $10 \mathrm{nM}$ insulin, and antibiotics). The glucose and lactate levels were selected to approximate ovine fetal levels (14).

All aspects of animal care and use were reviewed and approved by the institutional animal care and use committee.

Experimental design. In a typical experiment, after adherence, hepatocytes were cultured in standard medium supplemented with the stable isotope of interest at a $10-15 \%$ target enrichment. The medium was sampled at 0 and $24 \mathrm{~h}$, and then analyzed for amino acid concentration and enrichment as outlined below. Preliminary data demonstrated linear changes in both MPE and serine/glycine concentration changes over time. For determination of serine to glycine interconversion, $\left[1-{ }^{13} \mathrm{C}_{1}\right]$ serine was used as the tracer. For assessment of glycine to serine interconversion, $\left[1-{ }^{13} \mathrm{C}_{1}\right]$ glycine and $\left[2-{ }^{13} \mathrm{C}_{1}\right]$ glycine were used as the tracers. These two stable isotopes allow the determination of the contribution of the combined action ("coupling") of GCE and SHMT to the biosynthesis of serine from glycine compared with the contribution of SHMT alone. The degree of coupling of these two enzymes was expressed as the ratio of the 24-h serine $M+1$ MPE from $\left[2-{ }^{13} \mathrm{C}_{1}\right]$ glycine/24-h serine MPE from $\left[1{ }^{13} \mathrm{C}_{1}\right]$ glycine. A ratio $=1$ indicates the absence of coupling, whereas a ratio $=2$ suggests complete coupling of these GCE and SHMT. For further evidence supporting or refuting coupling of GCE and SHMT, and to investigate the contribution of the glyoxalate pathway to serine biosynthesis, studies were performed with $\left[1,2-{ }^{13} \mathrm{C}_{2}\right]$ glycine, $\left[2-{ }^{13} \mathrm{C}_{1}{ }^{15} \mathrm{~N}_{1}\right]$ glycine, and $\left[1,2-{ }^{13} \mathrm{C}_{2}{ }^{15} \mathrm{~N}_{1}\right]$ glycine.

Changes in medium serine and glycine concentrations over $24 \mathrm{~h}$ were studied in parallel cultures to which no serine or glycine isotopes had been added. The number of replicate cultures per isotope per animal ranged from 2 to 11 (mean of 4). Medium was harvested by aspirating with a sterile pipette at the indicated times, followed by centrifugation $(10,000 \times g, 30$ $\mathrm{s}$ at $4^{\circ} \mathrm{C}$ ) and then the medium was snap frozen for subsequent analysis. As a control, medium was incubated without cells for $24 \mathrm{~h}$ and analyzed in a similar manner.

To determine the effect of medium serine concentration on hepatocyte serine production, experiments were performed under normal medium conditions (serine concentration approximately $0.24 \mu \mathrm{mol} / \mathrm{mL}$ ) and compared with medium conditions where the serine concentration was approximately 3.5 times the normal level (serine approximately $0.79 \mu \mathrm{mol} / \mathrm{mL}$ ).

For most of the results, a sampling time of $24 \mathrm{~h}$ was selected for the following reasons: 1 ) Initial cultures with multiple time points over $24 \mathrm{~h}$ demonstrated linear changes in both serine and glycine concentrations and enrichments (see Results); 2) cell viability was maintained over $24 \mathrm{~h}$ as determined by constant protein and total RNA content (13); 3) significant differences in serine and glycine enrichments were demonstrable by $24 \mathrm{~h}$ using the initial tracer enrichment levels that were selected; and 
4) There is a significant decrease in medium glutamine by 30 $\mathrm{h}$, precluding longer experimental studies.

Media amino acid determinations. For amino acid and mass spectral analysis, the frozen medium supernatant was rapidly thawed and deproteinized with $15 \%$ sulfosalicylic acid, and the $\mathrm{pH}$ was adjusted to 2.2 with $2.35 \mathrm{~N} \mathrm{LiOH}$. Samples were centrifuged and the supernatants analyzed for amino acid content with a JEOL-200A amino acid analyzer using norleucine as the internal standard.

Mass spectral isotope ratio analysis. All isotopes had a purity $\geq 98 \%$ atom\% excess (CIL, Woburn, MA). Medium containing stable isotopes was analyzed for serine and glycine mass spectral isotope ratios following the methods previously described for amino acids (15). Analyses were performed on a Hewlett-Packard 5890 gas chromatograph fitted with a 7673T Autosampler and interfaced to a 5970 mass selective detector and a Hewlett-Packard-9000 workstation. Multiple ion selection was performed on derivatized samples. Peaks for serine enrichment were recorded at masses of 390-394. Peaks for glycine enrichment were recorded at masses 246-249. These peaks represent the M-57 moiety from the $t$-butyl-dimethylsilyl derivative of both amino acids. Aliquots of media obtained at time 0 and subsequent time points were analyzed for MPE. Specimens were analyzed in triplicate.

Calculations. The MPE was calculated by using the difference in peak area ratios between unenriched and enriched samples according to the following calculation:

$$
\mathrm{MPE}=\left\{\left(R_{\text {sample }}-R_{\text {stand }}\right) /\left[1+\left(R_{\text {sample }}-R_{\text {stand }}\right)\right]\right\} \times 100
$$

where $R_{\text {sample }}$ is the ratio of the $\mathrm{M}+1 / \mathrm{M}$ peak areas in the labeled sample, and $R_{\text {stand }}$ is the ratio of the $\mathrm{M}+1 / \mathrm{M}$ peak areas in the unlabeled standard. The stable isotope enrichments of both substrate and product were corrected for the natural background occurrence of the isotopomers of these molecules as described by Biemann (16). Although the interpretation of the results of some stable isotope studies may not be affected by this correction, failure to make this adjustment can produce spurious enrichments which may result in inaccurate interpretations of the data (17-19). In addition, a "skew correction" was applied which adjusts for the fact that the abundances in the gas chromatography-mass spectrometry spectrum of a labeled molecule are different from those in the same molecule which is unlabeled (19).

Tracer concentration in the media (micromole $\cdot \mathrm{mL}^{-1}$ ) was obtained by multiplying the amino acid concentration of the tracer in the media $\times$ its MPE $(\%) \times 0.01$.

Statistical methods. Values are expressed as the mean \pm SEM. Net positive values over $24 \mathrm{~h}$ for MPE, tracer concentration and amino acid values indicate an increase in the medium over this time period, and negative values indicate a decrease in amount in the medium. Twenty-four-hour changes of enrichment or tracer concentrations in the media were determined to be significantly different from 0 by the paired, two-tailed $t$ test. Comparison of corrected versus uncorrected enrichments were done by the paired, two-tailed $t$ test. Comparisons in enrichment between various isotopes were performed by the unpaired, two-tailed $t$ test. Enrichment values of
$0.3 \%$ were considered to be the lower limit of reliable enrichment detection in this laboratory.

\section{RESULTS}

Study hepatocytes. Hepatocytes were isolated from 10 fetal lambs with a mean gestational age of $132.9 \pm 1.4 \mathrm{~d}$ (range of 123-142 d, with term gestation in the sheep being approximately $145 \mathrm{~d})$. Cell yield averaged over one billion cells/ isolation. Cell viability was always greater than $95 \%$ as assessed by trypan blue exclusion.

Change in medium serine and glycine concentration over time. Change in medium serine and glycine concentrations over $24 \mathrm{~h}$ was determined in nine different cultures from four different animals to which no serine or glycine stable isotopes were added. There was a net reduction of medium glycine concentration of $0.26 \pm 0.03 \mu \mathrm{mol} / 10^{6} \mathrm{cells} / 24 \mathrm{~h}$, and a net increase in medium serine of $0.12 \pm 0.02 \mu \mathrm{mol} / 10^{6}$ cells $/ 24 \mathrm{~h}$. Both changes were significantly different from 0 , with $p<$ 0.0001 . Thus, as previously demonstrated, primary cultures of fetal ovine hepatocytes maintain the fetal pattern of net serine biosynthesis and net glycine utilization (13).

Linearity of MPE changes over time. To determine the appropriate times for medium sampling for the assessment of serine and glycine interconversion, multiple MPE sampling time points (3-5 time points per culture) were obtained over 24 $\mathrm{h}$ for each of the isotopes studied. For all cultures with $\geq 3$ sampling times in $24 \mathrm{~h}(n=87)$, the mean $r$ value for the regression of MPE versus time was $0.903 \pm 0.11$. A representative example is shown in Figure 2 where, after the addition of $\left[1,2-{ }^{13} \mathrm{C}_{2}{ }^{15} \mathrm{~N}_{1}\right]$ glycine as the tracer at time 0 , there is a linear increase in $\mathrm{M}+3$ serine and linear decline in $\mathrm{M}+3$ glycine over time.

Stable isotope data: glycine tracers. Table 1 demonstrates the 24-h change in medium glycine isotopomer enrichments for

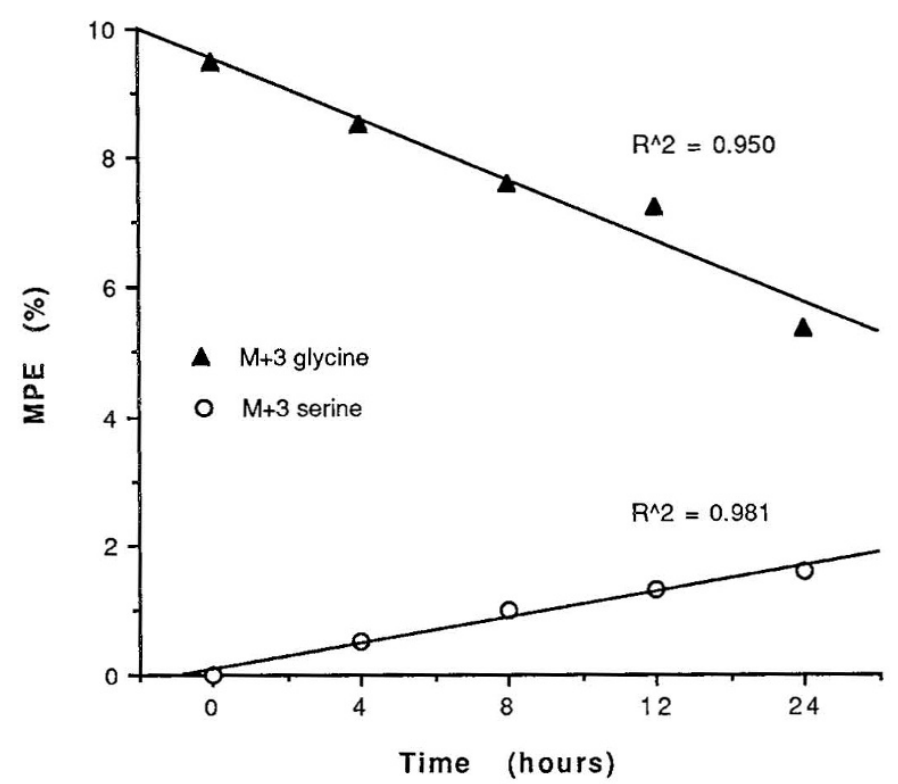

Figure 2. Changes in serine and glycine enrichment over time. Representative MPE data showing the linear changes in serine and glycine medium MPE over $24 \mathrm{~h}$ when $\left[1,2-{ }^{13} \mathrm{C}_{2}{ }^{15} \mathrm{~N}_{1}\right.$ ]glycine is added to the medium at time 0 . 
Table 1. Net decrease in media tracer glycine MPE over $24 \mathrm{~h}$

\begin{tabular}{|c|c|c|c|c|c|}
\hline & {$\left[1{ }^{13} \mathrm{C}_{1}\right]$} & {$\left[2-{ }^{13} \mathrm{C}_{1}\right]$} & {$\left[1,2-{ }^{13} \mathrm{C}_{2}\right]$} & {$\left[2-{ }^{13} \mathrm{C}_{1}{ }^{15} \mathrm{~N}_{1}\right]$} & {$\left[1,2-{ }^{13} \mathrm{C}_{2}{ }^{15} \mathrm{~N}_{1}\right]$} \\
\hline Starting MPE (\%) & $10.7 \pm 0.2$ & $12.2 \pm 0.4$ & $9.8 \pm 0.2$ & $12.1 \pm 0.5$ & $10.6 \pm 0.6$ \\
\hline \multicolumn{6}{|c|}{ 24-h change in MPE $(\%) \dagger$} \\
\hline$M+1$ & $-2.0 \pm 0.2 *$ & $-2.8 \pm 0.2^{*}$ & 0 & 0 & 0 \\
\hline $\mathrm{M}+2$ & & & $-2.6 \pm 0.3^{*}$ & $-2.8 \pm 0.3^{*}$ & 0 \\
\hline $\mathrm{M}+3$ & & & & & $-1.9 \pm 0.2^{*}$ \\
\hline Replicate cultures & 16 & 11 & 11 & 12 & 12 \\
\hline Number of animals & 3 & 4 & 4 & 4 & 4 \\
\hline
\end{tabular}

${ }^{*}$ Twenty-four-hour MPE change significantly different from $0, p<0.001$.

$\uparrow$ Positive value indicates increase in medium enrichment, negative value indicates decline in media enrichment.

each of the five glycine tracers studied. The observed dilution of enrichment implies active synthesis of unlabeled glycine at the same time a net decline in the medium glycine concentration is occurring. The comparable decrease in glycine MPE with all of the tracers suggests a comparable rate of glycine synthesis in all cultures.

Figure $3 A$ presents the changes in medium over $24 \mathrm{~h}$ when hepatocytes were cultured in medium enriched with either $\left[1-{ }^{13} \mathrm{C}_{1}\right]$ glycine or $\left[2-{ }^{13} \mathrm{C}_{1}\right]$ glycine as the tracer. To factor out the effect of initial tracer enrichment on the amount of labeled serine produced, the bars in this figure represent the 24-h change in medium serine MPE for each serine isotopomer as a percent of the starting MPE of the glycine tracer. There is a significant production of $M+1$ serine from $\left[1-{ }^{13} C_{1}\right]$ glycine, which would occur via the action of SHMT. As seen in Figure 1 , GCE produces $\mathrm{CO}_{2}$ from the first carbon in glycine, and methylene-THF from the second carbon. With $\left[1-{ }^{13} \mathrm{C}_{1}\right]$ glycine, under the action of GCE the ${ }^{13} \mathrm{C}$ label is lost as ${ }^{13} \mathrm{CO}_{2}$. Thus $\mathrm{M}+1$ serine can only be produced by $\left[1-{ }^{13} \mathrm{C}_{1}\right]$ glycine serving as a substrate for SHMT.

As shown in Figure $3 A$, when $\left[2-{ }^{13} \mathrm{C}_{1}\right]$ glycine is used as the tracer, the production of $\mathrm{M}+1$ serine is twice as great as that seen when $\left[1-{ }^{13} \mathrm{C}_{1}\right]$ glycine is used as the tracer. In Figure 1 it can be seen that $M+1$ serine can be produced from $\left[2-{ }^{13} \mathrm{C}_{1}\right]$ glycine either by glycine functioning as a methyl donor in the GCE pathway (i.e. carbon "B" in glycine becomes the 3 carbon in serine), or by glycine serving as substrate for SHMT (i.e. carbon 2 in glycine becomes the 2 carbon in serine). Under the action of SHMT, either $\left[1-{ }^{13} \mathrm{C}_{1}\right]$ glycine or $\left[2-{ }^{13} \mathrm{C}_{1}\right]$ glycine will produce $\mathrm{M}+1$ serine (the label appearing at the 1 and 2 carbon positions of serine, respectively). However, only $\left[2-{ }^{13} \mathrm{C}_{1}\right]$ glycine (and not $\left[1-{ }^{13} \mathrm{C}_{1}\right]$ glycine) could result in the production of $\mathrm{M}+2$ serine. This would occur by labeled carbon being derived from both the GCE and SHMT reactions occurring sequentially. The $2: 1$ ratio of $\mathrm{M}+1$ serine from $\left[2-{ }^{13} \mathrm{C}_{1}\right]$ glycine to $\mathrm{M}+1$ serine from $\left[1-{ }^{13} \mathrm{C}_{1}\right]$ glycine suggests a significant degree of coupling of GCE and SHMT. This 2:1 ratio was similar when either the cumulative data for all cultures enriched with these isotopes were used (11 replicate cultures in 4 animals and 16 replicates in 3 animals for $\left[2-{ }^{13} \mathrm{C}_{1}\right]$ glycine and $\left[1-{ }^{13} \mathrm{C}_{1}\right]$ glycine, respectively) (ratio $=$ 2.1 ), or when culture data where $\left[2-{ }^{13} \mathrm{C}_{1}\right]$ glycine and $\left[1-{ }^{13} \mathrm{C}_{1}\right]$ glycine were studied in parallel cultures from the same fetus ( 1 animal with 11 and 3 replicate cultures, respectively) $($ ratio $=1.7)$. This latter group of studies is more specific in that possible variables such as cell density and viability are factored out.
Further evidence for coupling of GCE and SHMT comes from the production of $\mathrm{M}+2$ serine from $\left[2-{ }^{13} \mathrm{C}_{1}\right]$ glycine (Fig. $3 A$ ). This should only occur by the sequential action of GCE and SHMT.

Figure $3 B$ demonstrates the changes in serine isotopomer enrichment over $24 \mathrm{~h}$ with the initial tracer being [1,2${ }^{13} \mathrm{C}_{2}$ ]glycine, $\left[2-{ }^{13} \mathrm{C}_{1}{ }^{15} \mathrm{~N}_{1}\right]$ glycine, or $\left[1,2-{ }^{13} \mathrm{C}_{2}{ }^{15} \mathrm{~N}_{1}\right]$ glycine. As described above for Figure $3 A$, the same correction was made for the initial tracer enrichment. There are two potential ways that serine could be produced from glycine via the glyoxalate pathway as seen in Figure 1: 1) by deamination of glycine before its conversion to serine by SHMT, and 2) loss of an amino group by glycine with subsequent donation of the " $\mathrm{B}$ " $\mathrm{CH}_{2}-\mathrm{THF}$ to another glycine molecule. If the first pathway were active, there should be production of $\mathrm{M}+1$ glycine from $\left[2-{ }^{13} \mathrm{C}_{1}{ }^{15} \mathrm{~N}_{1}\right]$ glycine and $\mathrm{M}+2$ glycine from $\left[1,2-{ }^{13} \mathrm{C}_{2}\right.$ ${ }^{15} \mathrm{~N}_{1}$ ] glycine (i.e. loss of the ${ }^{15} \mathrm{~N}$ label in both cases). As shown in Table 1, this did not occur. Also, as demonstrated in Table 1 , the decline in $\mathrm{M}+2$ glycine enrichment over $24 \mathrm{~h}$ is similar for $\left[1,2-{ }^{13} \mathrm{C}_{2}\right]$ glycine and $\left[2-{ }^{13} \mathrm{C}_{1} 15 \mathrm{~N}_{1}\right]$ glycine, which would not occur if glycine were significantly deaminated. Additional evidence supporting the lack of deamination/reamination of glycine are the similar enrichments of $\mathrm{M}+2$ serine from [1,2$\left.{ }^{13} \mathrm{C}_{2}\right]$ glycine, $\mathrm{M}+2$ serine from $\left[2{ }^{13} \mathrm{C}_{1}{ }^{15} \mathrm{~N}_{1}\right]$ glycine, and $\mathrm{M}+3$ serine from $\left[1,2-{ }^{13} \mathrm{C}_{2}{ }^{15} \mathrm{~N}_{1}\right]$ glycine. It would be expected that there would be a relatively greater enrichment of $\mathrm{M}+2$ serine from $\left[1,2-{ }^{13} \mathrm{C}_{2}\right]$ glycine if significant glycine deamination were occurring. The second scenario of glyoxalate pathway activity (i.e. loss of an amino group by glycine with subsequent donation of the "B" $\mathrm{CH}_{2}$-THF to another glycine) is more difficult to prove directly because the THF pool could be labeled either via GCE or the glyoxalate pathway. However, it is unlikely to be a major source of serine production because deamination of glycine is a prerequisite step, and glycine deamination doesn't appear to be active for the reasons noted above.

In the absence of an active glyoxalate pathway production of serine (see above), production of $\mathrm{M}+1$ serine from [1,2$\left.{ }^{13} \mathrm{C}_{2}\right]$ glycine, $\left[2-{ }^{13} \mathrm{C}_{1}^{15} \mathrm{~N}_{1}\right]$ glycine, or $\left[1,2-{ }^{13} \mathrm{C}_{2}{ }^{15} \mathrm{~N}_{1}\right]$ glycine (Fig. $3 B$ ) would occur only if ${ }^{13} \mathrm{C}$-labeled methylene-THF is produced from any one of these tracers by the action of GCE followed by use of the labeled methylene-THF and unlabeled glycine by the action of SHMT. This provides further support for the combined action of GCE and SHMT in these fetal ovine hepatocytes.

Stable isotope data: serine tracer. When $\left[1-{ }^{13} \mathrm{C}_{1}\right]$-L-serine tracer was added to the medium at time 0 , there was a decline of $M+1$ serine from $18.5 \pm 0.6$ to $7.1 \pm 0.7 \%$ enrichment over 

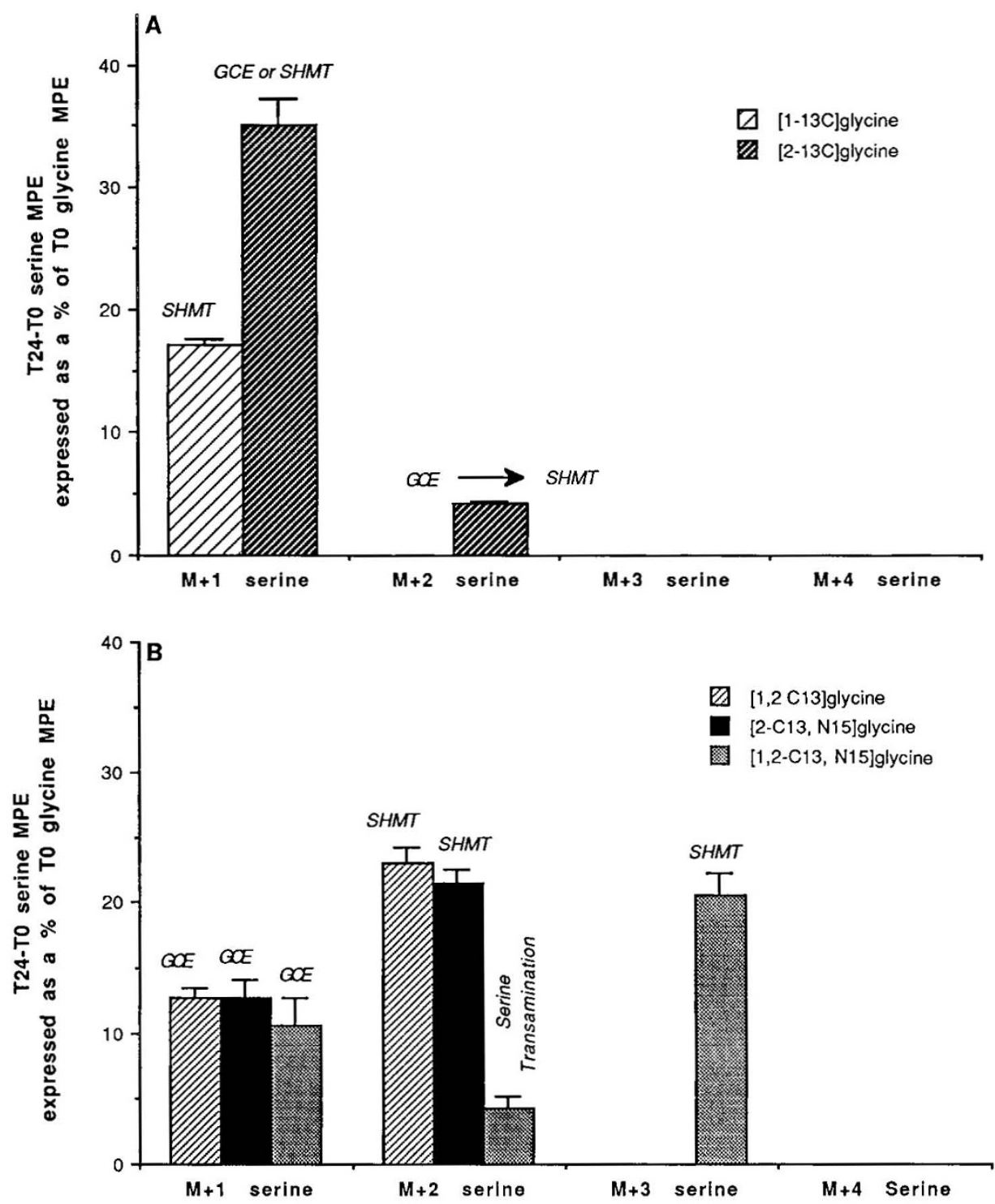

Figure 3. $(A$ and $B)$ Change in serine enrichment over $24 \mathrm{~h}$ expressed as a percent of initial glycine enrichment. Bars represent the mean change in medium enrichment of serine isotopomers over $24 \mathrm{~h}$ expressed as a percent of the starting enrichment for various glycine tracers. This factors out the effect of the glycine enrichment on the magnitude of the labeled serine produced. Error bars indicate SEM. For each bar, the mean isotopomer change over $24 \mathrm{~h}$ is significantly different from 0 ( $p<0.005$ for all isotopomers). SHMT and GCE indicate scrine which could only have been produced from glycine via SHMT or GCE, respectively. SHMT or GCE indicates that SHMT and GCE are simultaneously acting on the glycine substrate pool to produce serine. GCE $\rightarrow$ SHMT indicates two sequential reactions whereby there is initial glycine cleavage to methylene-THF, and this specific methylene-THF combines with glycine through the action of SHMT to produce serine. Transamination indicates reversible transamination through glyoxalate.

$24 \mathrm{~h}$ (implying dilution of the serine pool by serine synthesis) and an increase in $\mathrm{M}+1$ glycine from 0 to $0.9 \pm 0.1 \%$ enrichment. Both of these changes were significantly different from $0(p<0.0001)$.

Table 2 shows changes in serine concentration and enrichments between the two media with different serine concentrations. These data demonstrate that both net serine production and the extent of glycine to serine conversion are a function of serine concentration.

Tracer concentration studies. Table 3 demonstrates the glycine and serine tracer concentration changes (i.e. MPE $\times$ amino acid concentration) in the medium over $24 \mathrm{~h}$ for each of the glycine tracers used. The ratios of serine:glycine tracer concentrations averaged 0.27 (range of $0.22-0.35$ ).
Because SHMT is a bidirectional enzyme, we investigated the change in glycine tracer concentration after the addition of $\left[1-{ }^{13} \mathrm{C}_{1}\right]$-L-serine to the medium. Figure 4 demonstrates that when labeled serine is added to minimal essential medium (which has a serine concentration at which there is net serine production and glycine consumption by cultured fetal hepatocytes), labeled glycine does appear in the medium. This indicates the reversibility of the interconversion of serine to glycine in vitro.

\section{DISCUSSION}

In studies of various adult animal species, the liver exhibits a net uptake of both serine and glycine (5, 9-11). In contrast, 
Table 2. Change in medium serine concentration and enrichments over 24 h in "low" vs "high" serine medium

\begin{tabular}{cccc}
\hline $\begin{array}{c}\mathrm{T}_{0} \text { serine } \\
\text { concentration }\end{array}$ & $\begin{array}{c}\mathrm{T}_{24}-\mathrm{T}_{0} \text { serine } \\
\text { concentration } \\
(\mu)\end{array}$ & $\begin{array}{c}\mathrm{M} \text { MPE as a \% of } \mathrm{T}_{0}\left[1,2{ }^{13}\right. \\
(\mu \text { mol/million cells }) \S\end{array}$ & $\mathrm{C}_{2}{ }^{15} \mathrm{~N}_{1}$ ]glycine tracer MPE \\
\hline 238 & $120 \pm 20$ & $\mathrm{M}+3$ serine & $20.9 \pm 1.6$ \\
790 & $-120 \pm 30^{*}$ & $\mathrm{M}+3$ serine & $9.9 \pm 2.5^{*}$ \\
\hline
\end{tabular}

Data from six replicate cultures in three animals.

$\S$ Positive value indicates an increase and negative value a decrease in medium serine concentration over $24 \mathrm{~h}$.

* Significantly different from value in low concentration serine media, $p<$ 0.05 .

Table 3. Corrected tracer concentration change over $24 \mathrm{~h}$ (nanomole tracer $/ \mathrm{mL}$ medium $/ 24 \mathrm{~h}$ )

\begin{tabular}{|c|c|c|c|c|c|}
\hline & {$\left[1-{ }^{13} \mathrm{C}_{1}\right]$} & {$\left[2-{ }^{13} \mathrm{C}_{1}\right]$} & {$\left[1,2{ }^{-13} \mathrm{C}_{2}\right]$} & $\left.2-{ }^{13} \mathrm{C}_{1}{ }^{15} \mathrm{~N}_{1}\right]$ & {$\left[1,2-{ }^{13} \mathrm{C}_{2}{ }^{15} \mathrm{~N}_{1}\right]$} \\
\hline \multicolumn{6}{|l|}{$\begin{array}{l}\text { Initial tracer } \\
\text { glycine }\end{array}$} \\
\hline M+1 glycine & -49.2 & -115.1 & & & \\
\hline $\mathrm{M}+2$ glycine & & & -89.0 & -67.3 & \\
\hline $\mathrm{M}+3$ glycine & & & & & -56.6 \\
\hline Total glycine & -49.2 & -115.1 & -89.0 & -67.3 & -56.6 \\
\hline \multicolumn{6}{|l|}{$\begin{array}{l}\text { Tracer serine } \\
\text { production }\end{array}$} \\
\hline$M+1$ serine & 10.9 & 26.1 & 8.3 & 9.6 & 5.7 \\
\hline$M+2$ serine & & 2.9 & 12.2 & 14.9 & 2.2 \\
\hline$M+3$ serine & & & & & 9.2 \\
\hline$M+4$ serine & & & & & \\
\hline Total serine & 10.9 & 29.0 & 20.5 & 24.5 & 17.1 \\
\hline $\begin{array}{c}\text { Ratio serine: } \\
\text { glycine }\end{array}$ & 0.22 & 0.25 & 0.23 & 0.36 & 0.30 \\
\hline $\begin{array}{l}\text { Replicate } \\
\text { cultures }\end{array}$ & 16 & 11 & 11 & 12 & 12 \\
\hline No. of animals & 3 & 4 & 4 & 4 & 4 \\
\hline
\end{tabular}

Blank values indicate an MPE value $\leq 0.3 \%$, which is considered to be the lowest accurate level of enrichment detection by gas chromatography-mass spectrometry in this laboratory.

in vivo studies in fetal sheep have demonstrated a net hepatic uptake of glycine but a net hepatic production of serine (20, 21). This suggests that serine and glycine have unique fetal metabolic characteristics when compared with their metabolism in the adult. These same studies in fetal sheep have shown a negligible uterine uptake of glycine but a large umbilical release of glycine from the placenta to the fetus $(20,21)$, and the converse for serine, a measurable net uterine uptake with no measurable release of this amino acid from the placenta to the fetus in both the mid- and late-gestation fetus $(7,22,23)$. Therefore, there is no apparent transfer of serine from the mother to the fetus. This establishes the fact that in the fetal sheep, serine requirements must be met by endogenous fetal serine production. A recent study suggests that a similar situation exists in the human fetus (24). Several studies have led to the hypothesis of interorgan cycling between the the placenta and the fetus (particularly the fetal liver) for these two amino acids $(2,23)$. The present studies were undertaken to confirm the in vivo findings of ovine fetal hepatic glycine uptake and serine production in an in vitro system, and to determine the relative contribution of specific metabolic pathways to serine biosynthesis.

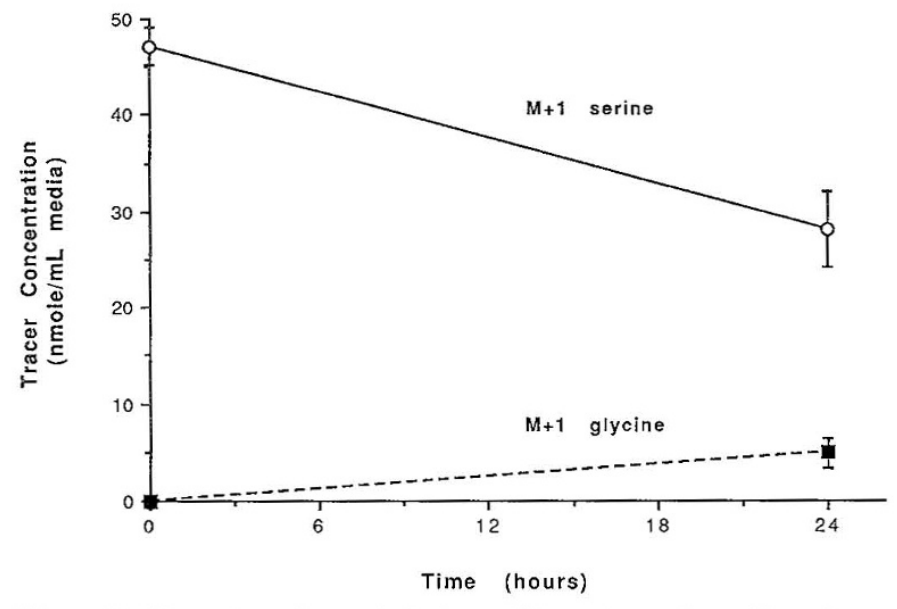

Figure 4. Change in serine and glycine enrichment over time with serine as the initial tracer. With the addition of labeled serine to the medium at time 0 , a significant decrease in serine tracer concentration and increase in the glycine tracer concentration occurs over $24 \mathrm{~h}$ (difference from 0 determined by paired $t$ test, $p<0.0001$ for both serine and glycine tracer concentration changes).

This study demonstrates that in ovine fetal hepatocytes cultured at "maternal" serine (low) concentrations there was a net consumption of glycine and a net production of serine. This same pattern was seen in a prior study of amino acid fluxes in primary culture of fetal sheep hepatocytes (13). In contrast, net serine utilization has been described for adult rat hepatocytes cultured at comparable serine concentrations (8).

The primary aim of this study was to identify the pathways by which glycine is converted to serine in fetal ovine hepatocytes by determining the enrichment of serine in the medium after the addition of stable isotopes of glycine. The pathways involved could include SHMT, GCE, or transamination (via the glyoxalate pathway).

In vivo studies of the fetal liver suggested the importance of a pathway involving the oxidation of glycine via GCE in that the net efflux of tracer $\mathrm{CO}_{2}$ and tracer serine from the liver were in approximately equimolar amounts (2). Tight coupling of GCE and SHMT has been described for the adult rat kidney (25). Coupling suggests that there is either a close physical proximitiy of these two enzymes, a small local pool of methylene-THF production, or both. In the present study, the combined action of GCE and SHMT in serine production from gycine is suggested in several ways. As seen in Figure $3 A$, $\mathrm{M}+1$ serine enrichment was twice as great from $\left[2-{ }^{13} \mathrm{C}_{1}\right]$ glycine when compared with $\left[1-{ }^{13} \mathrm{C}_{1}\right]$ glycine (MPE ratio of 2.1). The $\mathrm{M}+1$ serine peak from $\left[1-{ }^{13} \mathrm{C}_{1}\right]$ glycine is due to the action of SHMT, whereas the $\mathrm{M}+1$ serine peak from $\left[2-{ }^{13} \mathrm{C}_{1}\right]$ glycine is due to the action of SHMT and GCE both acting independently on a common glycine substrate pool.

The finding of $\mathrm{M}+2$ serine enrichment when $\left[2-{ }^{13} \mathrm{C}_{1}\right]$ glycine is the initial tracer (Fig. $3 \mathrm{~A}$ ) could occur only by the sequential action of GCE and SHMT. In addition, one would expect to find $\mathrm{M}+3$ serine enrichments with [1,2$\left.{ }^{13} \mathrm{C}_{2}\right]$ glycine and $\left[2-{ }^{13} \mathrm{C}_{1}{ }^{15} \mathrm{~N}_{1}\right]$ and an $\mathrm{M}+4$ serine enrichment with $\left[1,2-{ }^{13} \mathrm{C}_{2}{ }^{15} \mathrm{~N}_{1}\right]$ glycine (Fig. $3 B$ ), and these were not observed. It is possible that these enrichments are below the limit of detection. 
The changes in glycine enrichment in the medium over $24 \mathrm{~h}$ when either $\left[2-{ }^{13} \mathrm{C}_{1}{ }^{15} \mathrm{~N}_{1}\right]$ glycine or $\left[1,2-{ }^{13} \mathrm{C}_{2} 15 \mathrm{~N}_{1}\right]$ glycine is the tracer (Table 1) indicate that virtually no reversible transamination of glycine occurs. For $\left[2-{ }^{13} \mathrm{C}_{1}{ }^{15} \mathrm{~N}_{1}\right]$ glycine there is a significant decline in the $\mathrm{M}+2$ glycine enrichment, and no production of $\mathrm{M}+1$ glycine (i.e. glycine which has exchanged the labeled nitrogen), and for $\left[1,2-{ }^{13} \mathrm{C}_{2}{ }^{15} \mathrm{~N}_{1}\right]$ glycine there is a significant decline in the $\mathrm{M}+3$ glycine enrichment and no production of $\mathrm{M}+2$ glycine. When [1,2${ }^{13} \mathrm{C}_{2}{ }^{15} \mathrm{~N}_{1}$ ]glycine is the tracer there is no significant change in either the $M+1$ or $M+2$ glycine enrichment, suggesting that the glycine molecule remains intact. This suggests that reversible transamination of glycine through glyoxalate is either not active or not detectable (which might occur, for example, if the glyoxalate pool were very large) under these experimental conditions.

The significant increase in $\mathrm{M}+1$ serine enrichment from $\left[1,2-{ }^{13} \mathrm{C}_{2}{ }^{15} \mathrm{~N}_{1}\right]$ glycine (Fig. $3 B$ ) suggests an enriched methyl group derived from $\left[1,2-{ }^{13} \mathrm{C}_{2}{ }^{15} \mathrm{~N}_{1}\right]$ glycine combines with unlabeled glycine to produce serine. The increased $\mathrm{M}+2$ serine enrichment could occur in 2 ways: 1 ) from reversible transamination of the significant pool of $M+3$ serine whereby $M+3$ serine is converted to $M+2$ serine through exchange of the labeled nitrogen for unlabeled nitrogen, and 2) conversion of $M+3$ glycine to $M+2$ glycine by transamination, and then subsequent addition of an unlabeled methyl group to this $\mathrm{M}+2$ glycine. The former pathway is the most likely because no $\mathrm{M}+2$ glycine production was detected (Table 1 ).

In sum, these data suggest serine is produced from glycine via the simultaneous action of GCE and SHMT on the same glycine substrate pool, with minimal glycine transamination.

At a "fetal" plasma level of serine in the culture medium we were unable to demonstrate net medium serine production (Table 2). Because net serine production is found across the fetal liver in vivo, it implies that the culture conditions may not exactly mimic the in vivo system (e.g. hormones, growth factors, etc). However, the pattern of the stable isotope data demonstrates that glycine to serine conversion is still active at the high "fetal" serine concentration, though at a somewhat reduced magnitude.

Based on the labeled glycine:serine tracer concentration data (Table 3), the present study demonstrates that of the extracellular glycine used by cultured fetal ovine hepatocytes, approximately $30 \%$ is directed to serine synthesis. The carbon skeleton source for the remainder of the serine produced was not determined in these experiments. In adult tissues, serine biosynthesis has been studied in detail, and three different pathways of serine biosynthesis described (26-29). Two of these pathways are through 3-carbon carbohydrate intermediates involving the phosphorylated and nonphosphorylated pathways of glucose degradation. These pathways have not yet been investigated either in vivo across the fetal liver or in fetal hepatocyte cultures.

From this study and prior in vivo studies it is clear that the ovine fetal liver has unique serine and glycine fluxes through metabolic pathways compared with adult liver. Ascertaining the specific mechanisms by which this and other biochemical pathways operate in utero is important in determining the unique metabolism that occurs in fetal life. Stable isotope methodology can be much more specific than radioisotopic methodology in that it allows the ability to dissect metabolic events by labeling and quantifying individual atoms or combinations of atoms within the molecule of interest rather than just detecting total counts. Compared with in vivo studies, the use of a fetal ovine hepatocyte culture, which has been shown to retain fetal characteristics, has the advantage of allowing the investigation of multiple metabolic pathways simultaneously. Also, cell culture allows access to studies of metabolism in younger gestation fetuses where transhepatic catheter placement is not technically possible. We believe this is the first study which has confirmed and attempted to further define in vivo metabolic findings using stable isotopes in an in vitro preparation.

Acknowledgments. The authors gratefully acknowledge the able technical assistance of Gayle Jones and Natalie Nikolayevsky.

\section{REFERENCES}

1. Bismut H, Plas C 1989 Pathways of glycogen synthesis from glucose during the glycogenic response to insulin in phases of cellular proliferation in culturc. Biochem J 245:609-612

2. Cetin I, Fennessey PV, Quick Jr AN, Marconi AM, Meschia G, Battaglia FC, Sparks JW 1991 Glycine turnover and oxidation and hepatic serine synthesis from glycine in fetal lambs. Am J Physiol 260:E371-E378

3. Kennaugh JM, Bell AW, Meschia G, Battaglia FC 1987 Ontogenetic changes in protein synthesis rate and leucine oxidation during fetal life. Pediatr Res 22:688-692

4. Bismut $\mathrm{H}$, Poggi-Bach J, Plas C 1992 Consumption and production of amino acids by insulin-responsive cultured fetal rat hepatocytes: the particular case of serine. Biol Neonate $62: 37-46$

5. Huntington GB, Reynold CK 1987 Oxygen consumption and metabolite flux of bovine portal-drained viscera and liver. J Nutr 117:1167-1173

6. Lomax MA, Baird GD 1983 Blood flow and nutrient exchange across the liver and gut of the dairy cow. Br J Nutr 49:481-496

7. Marconi AM, Battaglia FC, Meschia G, Sparks JW 1989 A comparison of amino acid arteriovenous differences across the liver and placenta of the fetal lamb. Am J Physiol 257:E909-E915

8. Tanaka K, Kishi K, Ichihara A 1979 Biochemical studies on liver functions in primary cultured hepatocytes of adult rats. J Biochem 86:863-870

9. Barrett EJ, Gusberg R, Ferrannini E, Tepler J, Felig P, Jacob R, Smith D, DeFronzo RA 1986 Amino acid and glucose metabolism in the postabsorptive state and following amino acid ingestion in the dog. Metabolism 35:709-717

10. Davis MA, Williams PE, Cherrington AD 1984 Effect of a mixed meal on hepatic lactate and gluconeogenic precursor metabolism in dogs. Am J Physiol 247:E362E369

11. Pere MC, Gilbert M, Assan R, Battaglia FC 1987 Studies of gut and hepatic metabolism in conscious rabbits. Am J Physiol 252:E573-E580

12. Sturma, JA, Gaull GE, Raiha NRC 1988 DNA synthesis from the B-carbon of serine by fetal and mature human liver. Biol Neonate 27:17-22

13. Townsend SF, Thureen PJ, Hay Jr WW, Narkewicz MR 1993 Development of primary culture of ovine fetal hepatocytes for studies of amino acid metabolism and insulinlike growth factors. In Vitro Cell Dev Biol 29A:592-596

14. Battaglia FC, Meschia G 1986 Fetal and placental metabolism. Part I. Oxygen and carbohydrates. In: Battaglia FC, Meschia G (cds) An Introduction to Fetal Physiology. Academic Press, Orlando, FL, pp 70-95

15. Loy GL, Quick Jr AN, Teng CC, Hay Jr WW, Fennessey PV 1990 Versatile stable isotope technique for the mcasurement of amino acids and keto acids. Comparison with radioactive isotopes and its use in measuring in vivo disposal rates. Anal Biochem 185:1-9

16. Biemann K 1962 The mass spectra of isotopically labeled molecules. In: Biemann K (ed) Mass Spectrometry: Organic Chemical. McGraw-Hill, New York, pp 223-227

17. Buckley WT, Huckin ST, Eigendorf GK 1985 Calculation of stable isotope enrichment for tracer kinetic procedurcs. Biomed Mass Spectrom 12:1-5

18. Rosenblatt J, Wolfe RR 1988 Calculation of substrate flux using stablc isotopes. Am J Physiol 254:E526-E531

19. Wolfe RR 1992 Determination of isotopic enrichment by GCMS. In: Wolfe RR (ed) Radioactive and Stable Isotope Tracers in Biomedicine: Principles and Practice of Kinetic Analysis. Wiley-Liss, New York, pp 49-86

20. Holzman IR, Lemons JA, Meschia G, Battaglia FC 1979 Uterine uptake of amino acids and placental glutamine-glutamate balance in the pregnant ewc. J Dev Physiol $1: 137-149$ 
21. Morris Jr FH, Adcock III EW, Paxson Jr CL, Greeley Jr WJ 1979 Uterine uptake of amino acids throughout gestation in the unstressed ewe. Am J Obstet Gynecol 135:601-608

22. Lemons JA, Schreiner RL 1983 Amino acid metabolism in the ovine fetus. Am Physiol 244:E459-E466

23. Moores RR, Carter BS, Quick AN, Delmonte S, Meschia G, Fennessey PV, Battaglia FC 1990 Placental and fetal serine metabolism in early fetal life. Pediatr Res 27:1090(abstr)

24. Cetin I, Marconi AM, Baggiani AM, Buscaglia M, Pardi G, Fennessey PV, Battaglia FC 1995 In vivo placental transport of glycine and leucine in human pregnancies. Pediatr Res 37:571-575
25. Lowry M, Douglas EH, Brosnan JT 1986 Serine synthesis in rat kidney: studies with perfused kidney and cortical tubules. Am J Physiol 250:F649--F658

26. Hayashi S, Tanaka T, Naito J, Suda M 1975 Dietary and hormonal regulation of serine synthesis in the rat. J Biochem 77:207-219

27. Sallach HJ, Carnie JA, Wahbi SD, Al-Tai AH 1972 Dietary and hormonal regulation of hepatic biosynthetic and catabolic enzymes of serine metabolism in rats. Endocrinology 91:1054-1063

28. Snell K 1984 Enzymes of serine metabolism in normal, developing and neoplastic rat tissues. Adv Enzyme Regul 22:325-100

29. Walsh DA, Sallach HJ 1966 Comparative studies on the pathways for serine biosynthesis in animal tissues. J Biol Chem 241:4068-4076 